\title{
The management of a patient with multiple infarcts with different etiologies
}

\author{
Andreea Elena LACRARU ${ }^{1,2}$, Catalina Liliana ANDREI ${ }^{1,2}$, Andreea CATANA ${ }^{1,2}$, \\ Crina Julieta SINESCU ${ }^{1,2}$ \\ 1 "Carol Davila" University of Medicine and Pharmacy, Bucharest, Romania \\ 2 "Bagdasar-Arseni" Emergency Clinical Hospital, Bucharest, Romania
}

\section{ABSTRACT}

72 yo male, presents for abdominal pain and motor deficiency of the left upper limb. Clinical examination reveal severe general condition, left brachial hemiparesis, right arm blood pressure (BP) 240/120 $\mathrm{mmHg}$, left arm BP 210/100 $\mathrm{mmHg}$, heart rate (HR) $110 \mathrm{bpm}$, arrhythmic, abdominal pain at superficial palpation, without other abnormalities. Biological: negative hs troponin I, positive D-dimers, positive CRP, GFR $38 \mathrm{ml} / \mathrm{min} / \mathrm{m} 2$, potasium $2.97 \mathrm{mmol} / \mathrm{l}$. ECG: Atrial fibrillation. Abdominal ultrasound: abdominal dilated aorta, dissection flap. Abdominal and pelvic CT scan: right renal infarction, multiple splenic infarction, abdominal aortic aneurysm with dissection. Underwent interventional treatment of the abdominal aortic dissection (EVAR). Particularity of the case: concomitant diagnosis of multiple infarction with different etiologies, for which therapeutic decision was challenging.
\end{abstract}

Keywords: multiple infarcts, anticoagulation, aortic dissection, EVAR

\section{INTRODUCTION}

The term of infarction refers to the occurrence of prolonged ischemia in a certain organ as a result of the inadequate blood supply to the affected area. It may be caused by artery blockages, rupture, mechanical compression or vasoconstriction. It may have different etiologies, like an obstruction in the vessel due to atherosclerotic plaque, arterial embolus or thrombus; ruptured of the vessel causing a loss of blood pressure downstream of the rupture; vasoconstriction of the vessel (e.g., myocardial infarction due to cocaine consumption) or compressed by something (e.g., tumor, hernia). Treatment and prognosis are different, depending on the etiology and location of the infarction [1-3].

We will present the case of a 72 yo male, presented for abdominal pain and motor deficiency of the left upper limb.

\section{CASE PRESENTATION}

A 72 years-old male patient, non-smoker was presented at the emergency room (ER) for severe diffuse abdominal pain, suddenly installed, 24 hours previously, without other associated phenomena and motor deficiency of the left upper limb, installed 4 hours previously.

His medical history: ischemic stroke 4 years ago, without a clear etiology, without motor or sensory deficiency (revealed by discharge papers), 10-years history of hypertension (HTN) with maximum sistolic BP of $170 \mathrm{mmHg}$.

He was in chronic treatment with metoprolol 50 $\mathrm{mg}$ /day and perindopril $10 \mathrm{mg} /$ day. No history of palpitations, chest pain or dyspnoea.

Clinical examination at presentation revealed severe general condition, afebrile, oxygen peripheral saturation was $98 \%$ spontaneous, conscious, cooperative, 
left brachial hemiparesis, no crural motor deficiency, positive Babinski on the lower left limb, no headache, equal pupils, right arm BP $240 / 120 \mathrm{mmHg}$, left arm BP 210/100 mmHg, HR 110 bpm, arrhythmic, holosystolic murmur in the mitral area, systolic murmur on the carotid arteries, no pulse at the left dorsal pedis and posterior tibial arteries, teguments with normal local temperature and color in both inferior limbs, no pulmonary rales, no systemic congestion, spontaneous abdominal pain and at superficial palpation, positive Murphy maneuver, no hydroaeric noises, normocrome urine, without other abnormalities.

In the ER department were collected biological tests that showed: negative hs troponin I $(10.6 \mathrm{ng} / \mathrm{l})$, positive D dimers (> $5 \mu \mathrm{g} / \mathrm{l})$ ), slightly elevated NT-proBNP $(740 \mathrm{pg} / \mathrm{ml}), \mathrm{Hb} 15.8 \mathrm{~g} / \mathrm{l}, \mathrm{WBC} 12,100 \mathrm{~mm}^{3}$ with $82 \%$ neutrophils, platelets $191,000 / \mathrm{mm}^{3}$, positive CRP (> 30 $\mathrm{mg} / \mathrm{dl}$ ), glycemia $110 \mathrm{mg} / \mathrm{dl}, \mathrm{BUN} 48 \mathrm{mg} / \mathrm{dl}$, GFR $38 \mathrm{ml} /$ $\mathrm{min} / \mathrm{m}^{2}$, sodium $134 \mathrm{mmol} / \mathrm{L}$, potasium $2.97 \mathrm{mmol} / \mathrm{l}$.

The ECG shows atrial flutter without significant changes (Figure 1).

Chest X-ray reveals slightly enlarged cardio-thoracic index, without pleural or lungs abnormalities. Chilaiditi syndrome. Abdominal X-ray: Hydroaeric levels in the ascending colon.
Abdominal ultrasound in the ER highlights abdominal dilated aorta with suspicion of dissection flap, hypoecoic area on the right kidney.

Echocardiography: slightly dilated left atrium $\left(38 \mathrm{ml} / \mathrm{m}^{2}\right)$, normal left ventricular function, moderate degenerative mitral regurgitation, normal diameters of the ascending and thoracic descending aorta, without dissection flap, without aortic regurgitation.

Given the clinical presentation and the outcome of the paraclinical investigations, we decided to hospitalize the patient in coronary care unit (CCU) department. We initiate treatment for controlling BP values with continuous nitroglycerin IV, with progressively increased doses, loop diuretic, heart rate control with beta-blocker IV and pain relief treatment.

Brain CT scan performed at admission reveals acute stroke of right medial cerebral artery (Figure 2).

Also, we performed an abdominal and pelvic CT scan with contrast that showed right renal infarction, multiple splenic infarction and abdominal aneurysm with dissection emerging from upper mesenteric artery origin to the right renal artery origin, non-progressive on the right renal artery (Figure 3 ).

The final diagnosis was: Embolic stroke of right medial cerebral artery, cardioembolic splenic infarction,

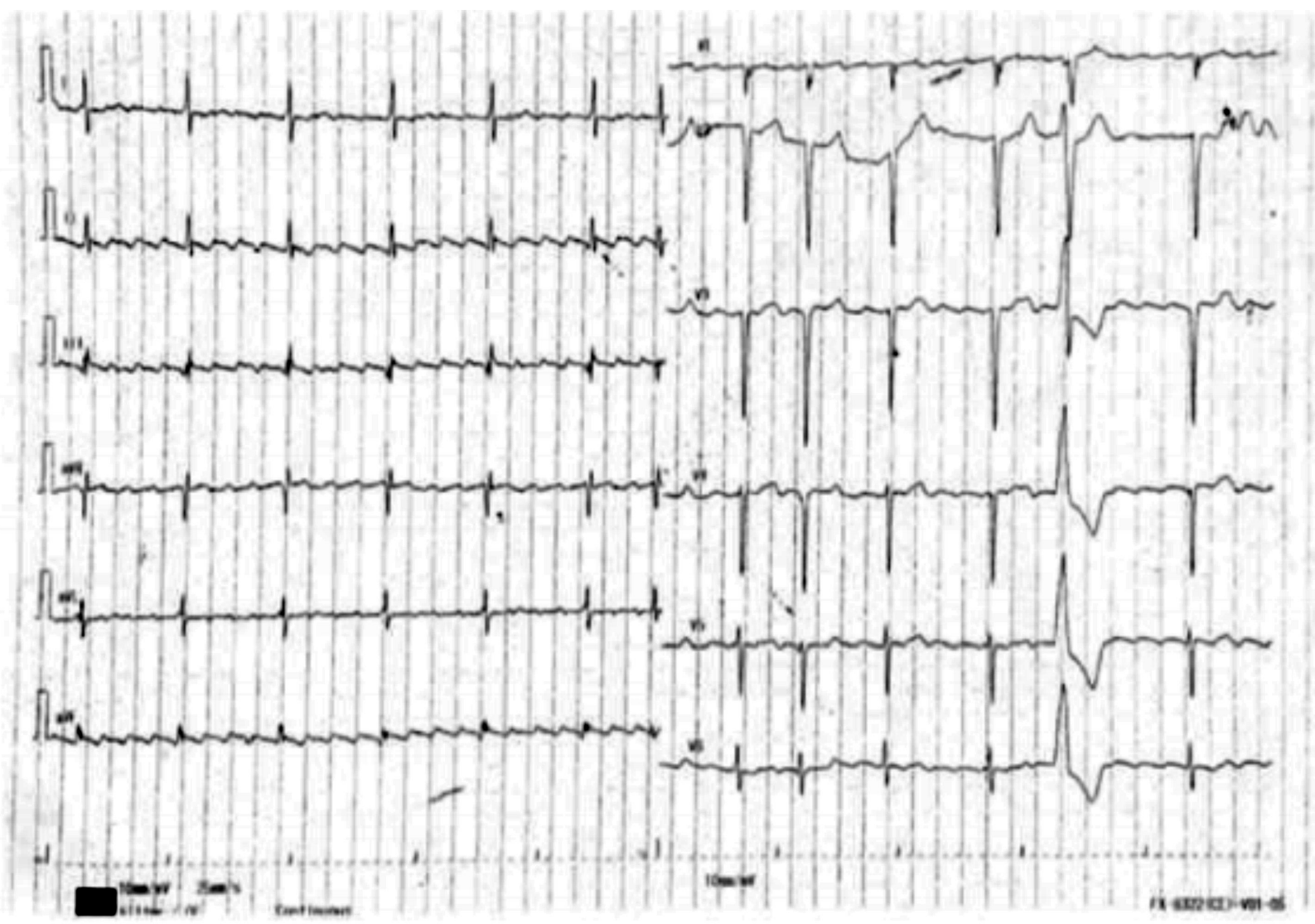

FIGURE 1. ECG 


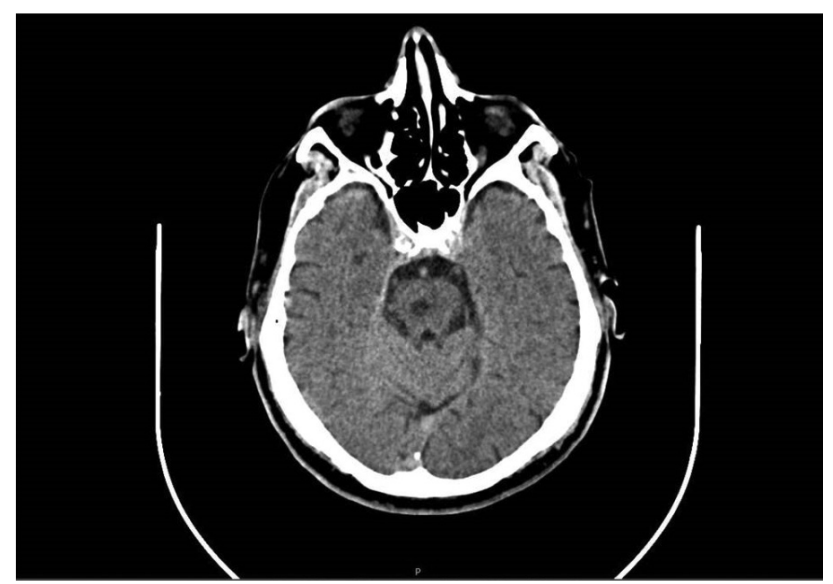

FIGURE 2. Acute stroke of right medial cerebral artery

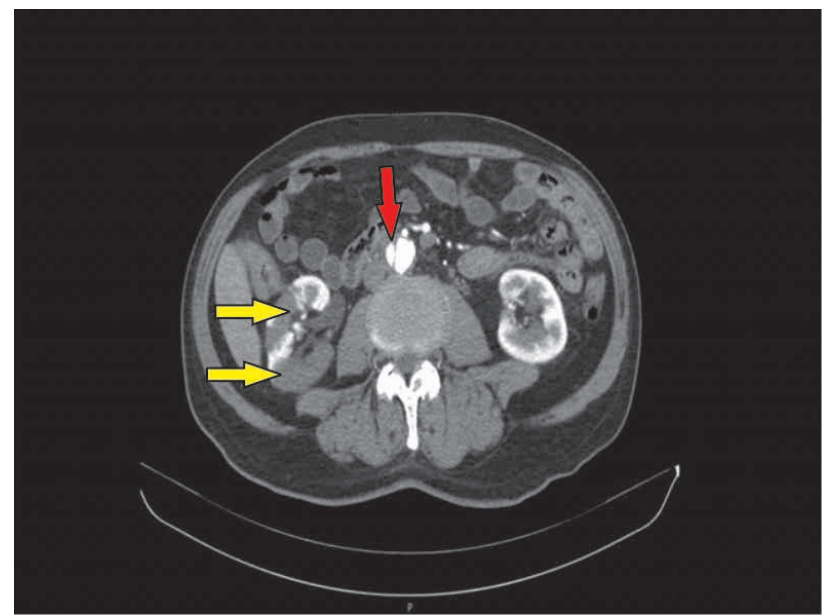

FIGURE 3. Aortic dissection fold (red arrow) and renal infarction (yellow arrow)

mesenteric infarction possible with both embolic and/ or flap dissection extension mechanism and right renal infarction, persistent atrial fibrillation, HTN.

We considered stroke and splenic infarction as having embolic etiology, in the context of persistent atrial fibrillation without previous anticoagulation, brain CT and abdominal CT scans showing that the dissection entry tear is below the origin of the splenic artery.

The right renal infarction was considered as a result of the hypoperfusion due to dissection of the abdominal aorta, that hadn't extended on the renal arteries (it stopped at the origin of renal arteries as the CT scan showed). Mesenteric infarction probably has double etiology (dissection of the aorta and embolism), considering that the dissection of the abdominal aorta encompasses the origin of the upper mesenteric artery, but does not reach the origin of the inferior mesenteric artery.

Therefore, our pacient underwent interventional treatment of the abdominal aortic dissection (EVAR) with good results and subsequently the pacient received chronic anticoagulation for secondary prevention of cardioembolic events.

\section{Follow-up}

During the hospitalization in our cardiology department his clinical and biological evolution was favorable with controlled BP values under treatment with calcium channel blocker, betablocker and loop diuretic. Clinical, biological and imaging (cardiac and abdominal ultrasound) at one year follow-up revealed the remission of the right brachial motor deficit, maintaining normal range BP values (prooved on 24 hours MATA), normal renal function (RFG $60 \mathrm{ml} / \mathrm{min} / 1.73 \mathrm{~m}^{2}$ ), normal intestinal transit, without occurrence of other embolic events under anticoagulant treatment with AVK.

\section{DISCUSSIONS}

An aortic dissection is a medical emergency in which the inner layer of the aorta tears, resulting in the appearance of a false lumen that can press or even block the true lumen, which can cause serious consequences such as internal bleeding [4].

The incidence of aortic dissection is estimated to be 5-30 cases per 1 million people per year. Approximately $75 \%$ of dissections occur in people aged $40-70$ years, with a peak in the range of $50-65$ years $[5,6]$.

The most used classification of the aortic dissection is the Stanford classification (type A if it involves any portion of the ascending aorta and type $B$ dissection that begins distal to the left subclavian artery and can affect the descending aorta and/or the aortic arch).

In-hospital mortality for aortic dissection is high, due to the fast progress nature and, sometimes, due to late diagnosis [7].

Patients with type A aortic dissection who undergo surgical treatment have a $30 \%$ mortality and patients who receive medical treatment have a $60 \%$ mortality. In the type B dissection patients, medically treated, the mortality is $10 \%$ and surgically treated patients with type B dissection have a $30 \%$ mortality. The highest mortality is in the first 7 days, from $1 \%$ to $2 \%$ of patients with aortic dissection die per hour for the first 24-48 hours [8].

Classically, patients with acute aortic dissection presents severe pain, suddenly installed, in the chest, back, or abdomen, depending of the location of the dissection. Only in $10 \%$ of patients aortic dissection is painless and this particularity is more common in those with neurologic complications from the dissection. $\mathrm{Hy}$ pertension may be preexisting or may be due from a catecholamine surge. An interarm blood pressure differential greater than $20 \mathrm{mmHg}$ should increase the suspicion of aortic dissection, but it does not rule it in [7].

In our case, we were facing a patient that presents multiple infarctions with different etiologies: cerebral (embolic), splenic (embolic), mesenteric (dissection of 
the abdominal aorta and possibly embolic), right kidney infarction (kidney hipoperfusion induced by dissection of the abdominal aorta) that require different therapeutic approach and who associates also dissection of the abdominal aorta. Given to the cardioembolic etiology of multiple infarction, the pacient need anticoagulant treatment, but we must consider the potential risk of progression of abdominal aortic dissection in the context of the anticoagulant treatment.

According to the aortic disease guideline the optimal treatment in complicated type $B$ aortic dissection is endovascular aortic repair (EVAR) [7].

In 1999, Dake et al. [9] first applied endovascular stent-graft to repair acute thoracic aortic dissection (TEVAR) successfully, Since then, EAVR has rapidly replaced open surgery due to its relative simplicity and lower risk. Two large series that used the International
Registry of Acute Aortic Dissection database shows that for complicated acute type B aortic dissection, EVAR is associated both with significantly improved early outcome and with midterm survival benefit at 5-year follow-up [10-14].

\section{CONCLUSIONS}

Acute aortic dissection is a dynamic process with a wide spectrum of clinical manifestations and presentations, which can delay the correct diagnosis.

In our case, the particularity of the case did not consist in the difficulty of quickly establishing the diagnosis, but in the concomitant diagnosis of multiple infarction with different etiologies, cardioembolic and dissection of the abdominal aorta, for which therapeutic decision was challenging.

Conflict of interest: none declared Financial support: none declared

\section{REFERENCES}

1. Valgimigli M, Bueno $\mathrm{H}$, Byrne RA, Collet JP, Costa F, et al.; ESC Scientific Document Group; ESC Committee for Practice Guidelines (CPG); ESC National Cardiac Societies. 2017 ESC focused update on dual antiplatelet therapy in coronary artery disease developed in collaboration with EACTS: The Task Force for dual antiplatelet therapy in coronary artery disease of the European Society of Cardiology (ESC) and of the European Association for CardioThoracic Surgery (EACTS). Eur Heart $\mathrm{J}$. 2018 Jan 14;39(3):213-260.

2. Olsen TS. Regional cerebral blood flow after occlusion of the middle cerebral artery. Acta Neurol Scand. 1986 Apr;73(4):321-37.

3. Eltawansy SA, Patel S, Rao M, Hassanien S, Maniar M. Acute Renal Infarction Presenting with Acute Abdominal Pain Secondary to Newly Discovered Atrial Fibrillation: A Case Report and Literature Review, Case Rep in Emergency Medicine. 2014;2014:981409.

4. Li L, Zhuang S, Qi S, Cui J, Zhou J, et al. Acute thoracic aortic dissection (stanford type B) complicated with acute renal failure. Case Rep Vasc Med. 2013;2013:693435.

5. Spittell PC, Spittell JA Jr, Joyce JW, Tajik AJ, Edwards WD, Schaff HV, Stanson AW. Clinical features and differential diagnosis of aortic dissection: experience with 236 cases
(1980 through 1990). Mayo Clin Proc. 1993 Jul;68(7):642-51.

6. Braverman AC, Schermerhorn M. Diseases of the aorta. In: Zipes DP, Libby P, Bonow RO, Mann DL, Tomaselli GF, Braunwald E, (eds.) Braunwald's Heart Disease: A Textbook of Cardiovascular Medicine. 11th ed. Philadelphia: Elsevier, 2019:Vol 2. 1295-1325.

7. Erbel R, Aboyans V, Boileau C, Bossone E, Bartolomeo RD, et al.; ESC Committee for Practice Guidelines. 2014 ESC Guidelines on the diagnosis and treatment of aortic diseases: Document covering acute and chronic aortic diseases of the thoracic and abdominal aorta of the adult. The Task Force for the Diagnosis and Treatment of Aortic Diseases of the European Society of Cardiology (ESC). Eur Heart J. 2014 Nov 1;35(41):2873-926.

8. Michaelis W, Santos AL Filho, Yokohama $R A$, et al. Dissecção aórtica de tipo $B$ de Stanford: relato de caso e revisão de literatura. J Vasc Bras. 2017 Jul-Sep; 16(3):252-257.

9. Glower DD, Fann JI, Speier RH, Morrison L, White WD, Smith LR, Rankin JS, Miller DC, Wolfe WG. Comparison of medical and surgical therapy for uncomplicated descending aortic dissection. Circulation. 1990 Nov;82(5 Suppl):IV39-46.
10. Dake MD, Miller DC, Semba CP, Mitchell RS, Walker PJ, Liddell RP. Transluminal placement of endovascular stent-grafts for the treatment of descending thoracic aortic aneurysms. N Engl J Med. 1994 Dec 29;331(26):1729-34.

11. Fattori R, Tsai TT, Myrmel T, Evangelista $A$, Cooper JV, Trimarchi S, Li J, Lovato L, Kische S, Eagle KA, Isselbacher EM, Nienaber CA. Complicated acute type B dissection: is surgery still the best option?: a report from the International Registry of Acute Aortic Dissection. JACC Cardiovasc Interv. 2008 Aug;1(4):395-402.

12. Fann JI, Smith JA, Miller DC, Mitchell RS, Moore KA, et al. Surgical management of aortic dissection during a 30-year period. Circulation. 1995 Nov 1;92(9 Suppl):Il113-21.

13. Trimarchi S, Nienaber CA, Rampoldi V, Myrmel T, Suzuki T, et al.; IRAD Investigators. Role and results of surgery in acute type B aortic dissection: insights from the International Registry of Acute Aortic Dissection (IRAD). Circulation. 2006 Jul 4;114(1 Suppl):I357-64.

14. Parsa CJ, Schroder JN, Daneshmand MA, McCann RL, Hughes GC. Midterm results for endovascular repair of complicated acute and chronic type B aortic dissection. Ann Thorac Surg. 2010 Jan;89(1):97-104. 